\title{
Virological aspects of neurological disease
}

\author{
A. P. WATERson \\ June D. Almeida \\ Department of Virology, Royal Postgraduate Medical School, London, W.12
}

\begin{abstract}
Summary
Viruses are now known to consist of only two major components; the nucleic acid which is essential for infectivity and an external covering to protect this. Visualization of this external shell by electron microscopy has revealed that viruses display distinctive arrangements of sub-units by which they can be both recognized and characterized. This has made it possible to classify viruses according to their structural and chemical features and such a classification has superseded earlier and essentially biological classifications without contradicting them.

The action of a virus upon a cell may take one of three forms. The virus in the process of replication may destroy the cell which it has infected (lytic action). A second possibility is that it may transform the cell to malignancy (oncogenic action). A third possibility is that the virus may remain latent within the cell for long periods with no obvious manifestations of its presence (symbiotic relationship). It is this last type of interaction between a virus and the host cell which appears to be of particular interest in the context of the nervous system.
\end{abstract}

\section{Introduction}

After many years of speculation on the nature of viruses, our knowledge of them as a group of microorganisms has now reached the stage at which they can be characterized, described and defined in such a way that subsequent findings will not contradict or invalidate the major statements, although they may expand and amplify them (Waterson, 1968). One such contemporary description would be as follows. A virus is a particle consisting of one type of nucleic acid, which is the genetic material, and a covering of protein whose primary, but not necessarily sole function is to protect this essential component. By itself the virus particle is biologically inert, but on gaining access to a suitable living cell it is capable of using the cell's synthetic mechanisms to produce progeny virus.

Some of the points contained in this description must be considered further. The unit of all life is the cell, and all cells require two types of nucleic acid, DNA and RNA, in addition to a battery of structural and functional proteins. The virus, on the other hand, has only one kind of nucleic acid and insufficient information in that for it to function as an independent living organism. This is why, on its own, a virus is biologically inert. An everyday analogy of a virus and its relationship with the cell it infects is that of a computer tape, which on its own has no function, but which on insertion into a computer will realize the information contained in it. The viral nucleic acid is the information-laden tape and the cell the computer, which not only reads off the genetic message but follows its instructions to turn out a new generation of virus particles identical to the original one.

Modern chemical methods have yielded considerable information about the nucleic acid part of viruses: electron microscopy, particularly of specimens prepared by the simple technique of negative staining, has thrown light on the manner in which the protein of viruses is arranged to protect their nucleic acid: biochemical studies have done much to elucidate the processes involved in viral multiplication and the intimate interactions between virus and cell which this involves.

The recognition of the virus particle as a transmissible nucleoprotein which becomes active only when it enters a cell is really the clue to many of the cardinal features of the pathogenesis, diagnosis and prophylaxis of the diseases which they cause. It makes it clear why the diagnostic virological laboratory must use living cells in some form in attempts at virus isolation (Fig. 1). It explains the difficulty of developing effective chemotherapeutic agents against viruses, as the action of a successful antibiotic against a bacterium depends upon the bacterium having metabolic processes sufficiently distinct to be inhibited without the host's cells being affected. In the virus-infected cell, however, the metabolism of cell and virus are so intimately fused that so far, with few exceptions, it has proved impossible to inhibit selectively those processes which are viral without seriously disturbing those processes which are cellular.

As well as these advances in fundamental aspects of virology a great number of new viruses have come to light because of the now widespread use of cell and tissue cultures in virus laboratories. In other 

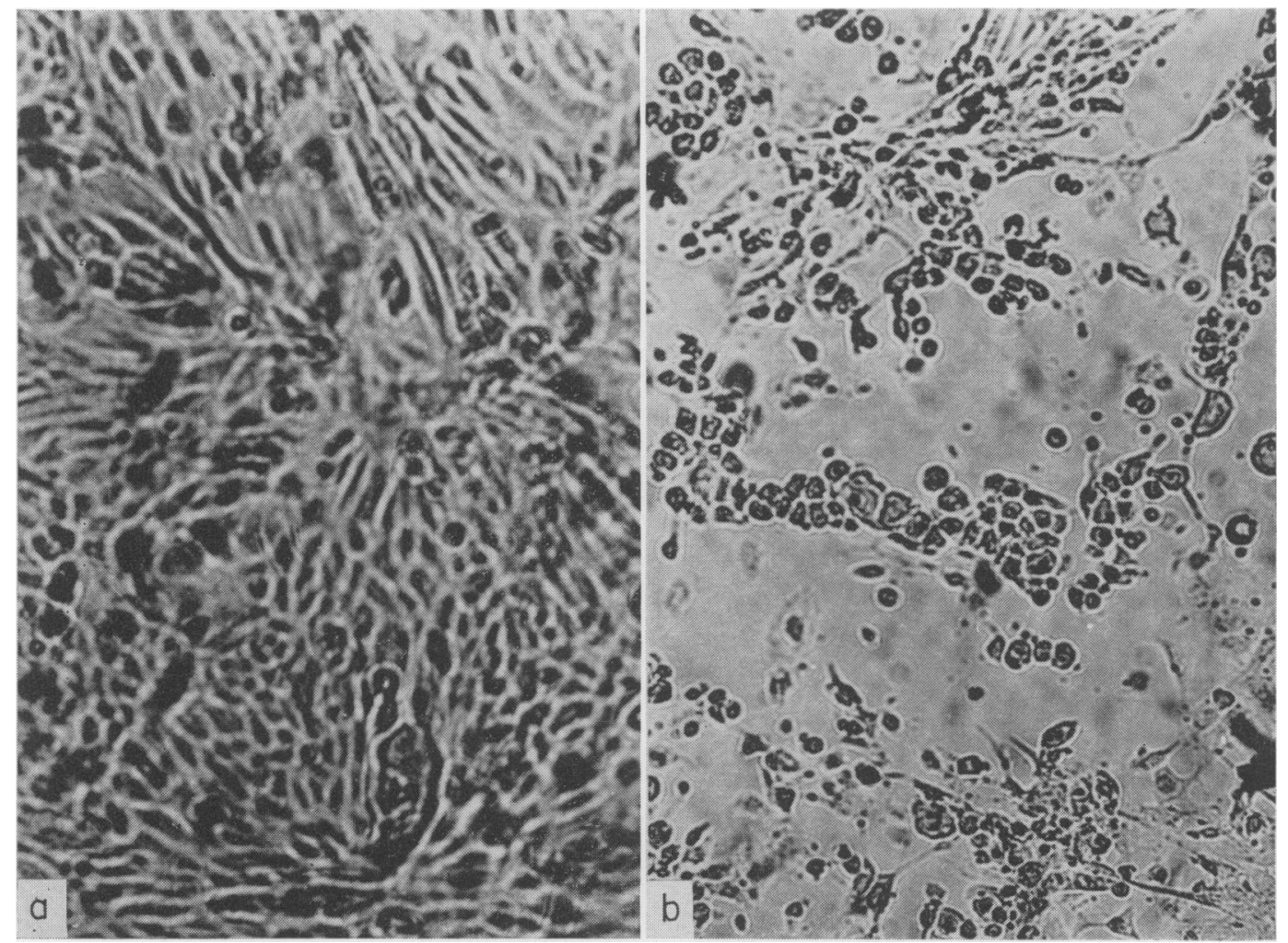

FIG. 1. (a) This micrograph shows the appearance of monkey kidney cells grown in vitro. The cells have proliferated in culture to form a continuous sheet on the glass wall of the culture vessel. (b) The same preparation as in (a), 2 days after infection with poliomyelitis virus. The cells are rounded up and in many cases have become detached from the glass. This appearance is known as a cytopathic effect (CPE).

words, virology has grown not only in depth, but also in breadth (Swain \& Dodds, 1967). This has necessitated the extension of existing systems of classification and a re-examination of their validity in the light of the new knowledge which has accumulated.

There are several fundamentally different ways of classifying viruses (Lwoff, Horne \& Tournier, 1962). For example, they can be grouped according to the diseases they cause. Thus a book of medical virology published in 1952 divides viruses into: (i) those causing disease of the nervous system, (ii) systemic virus infections, (iii) acute infections of the respiratory tract, and (iv) viral diseases with special effect on skin, mucous membranes, genitals and eyes (Rivers, 1952). Such a classification makes no allowance for the fact that one virus may fall into several of these categories, or that viruses which are in reality closely related may produce very different effects in different hosts, or for minor strain differences in the virus. The effect of a virus on the patient is of prime importance medically, but in taxonomy it is a broken reed.
In view of the manifest shortcomings of this and similar systems of classification, it is not surprising that virologists have turned to the new knowledge about the chemistry and morphology of viruses to provide just those fundamental, unchanging parameters by which viruses can be characterized, compared and segregated into meaningful groups (Almeida, 1963). Thus viruses are readily divided, or rather divide themselves, into two categories according to their type of nucleic acid, for, as has been stated, all viruses have only one type of nucleic acid, either DNA or RNA. Almost as taxonomically decisive is a major morphological feature of the virus particle, namely the arrangement of the protein molecules or sub-units which make up the protective coat. These protective coats, or, to be more scientific, capsids, reveal with the negative-staining technique two types of symmetry in their arrangement (Horne \& Wildy, 1961). Viruses display either helical symmetry, with protein units in a spiral (Fig. 2) or cubic symmetry, with protein units in a polyhedral form, usually in fact an icosahedron (Figs. 3 and 4). On 


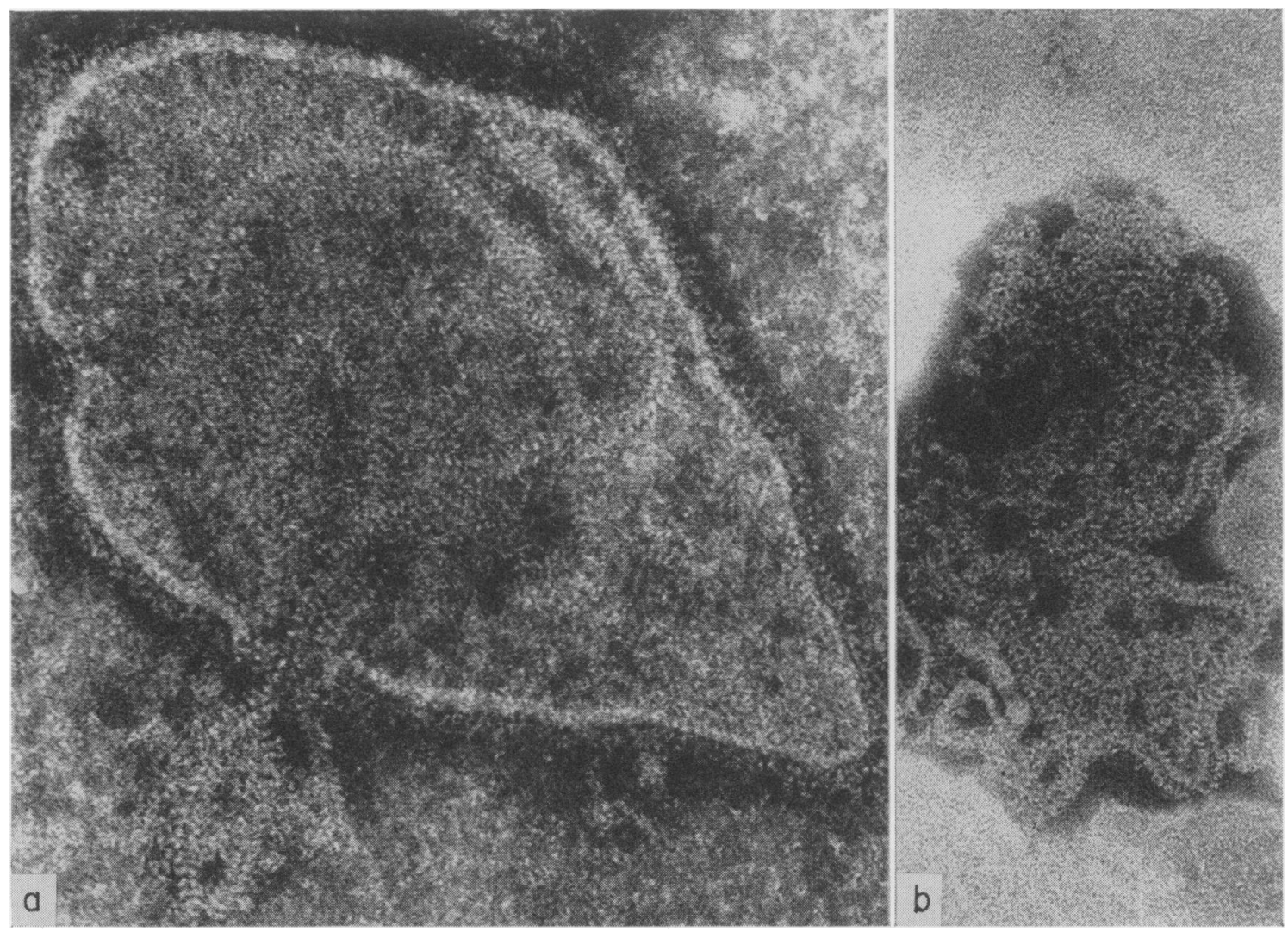

Fig. 2. (a) This figure shows a measles virus particle obtained from tissue culture. Although the whole virus particle is present it is damaged, so that the internal helical ribonucleoprotein component is visualized; this can be seen spilling out at the bottom left. The membrane enclosing this helix contains virally coded proteins but is, physically, cell-derived. $\times 200,000$. (b) A length of helix microscopically indistinguishable from that shown in (a), derived from a homogenate of brain tissue from a case of subacute sclerosing panencephalitis. The presence of this material adds further weight to the findings provided by immunological studies that measles virus is implicated in this disease. $\times 200,000$.

the basis of these two criteria, i.e. nucleic acid content and type of symmetry, viruses can be divided into four main physico-chemical types, viz. RNAcubic, RNA-helical, DNA-cubic and DNA-helical, and the last of these (DNA-helical) need not be considered here, as at present it contains only bacterial viruses. This classification has the merit that viruses are grouped on intrinsic, unchangeable features, and, of at least equal significance, it is now well established that within the categories there is considerable similarity of the virus-cell interaction. This is borne out by the fact that only morphologically identical viruses have ever been shown to have serological relationships, although the reverse is not necessarily true, i.e. morphological identity does not imply serological relationship. Needless to say, there are still a few uncertainties within this physicochemical grouping. For example, the type of symmetry of the arboviruses (Fig. 6a) has not been satisfactorily established, and the poxviruses (Fig. 5) seem to form a group on their own, but in general most of the viral pathogens of man and domestic animals can now be accorded a place within the scheme (Table 1).

As with any classification there are subsidiary properties of the objects under study which leak in an unsatisfactory way from one category to another, and viruses are no exception to this. For example, the result of infection of a cell by viruses may be one of three types.

First, the synthetic processes involved in production of new virus may be associated with death of the cell. This type of interaction is known as a lytic one, a term derived from the effect of bacterial viruses on bacteria. The effect produced by such lytic viruses on cells (Fig. 1) is described as a cytopathic effect (CPE), and perhaps the greatest number of animal viruses belong in this category. It is a favourite type of phenomenon for study in the laboratory because of 


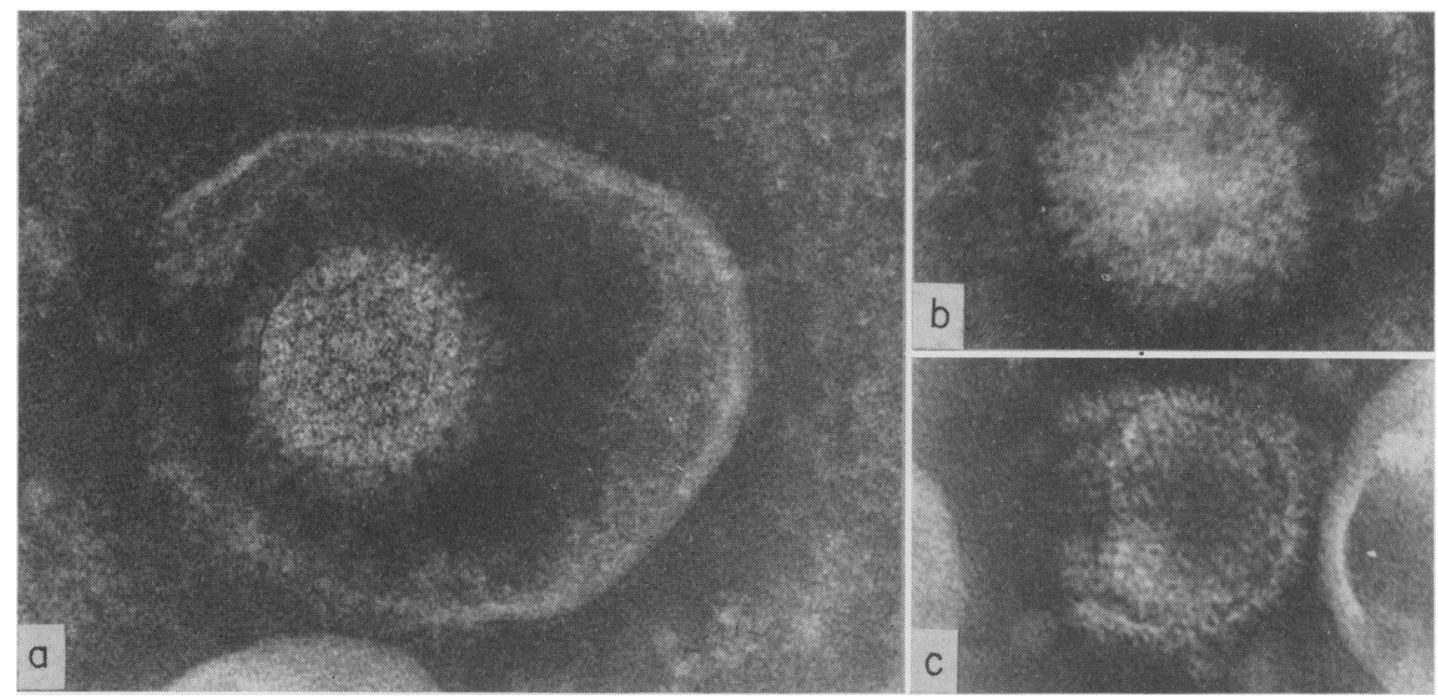

FIg. 3. (a) A typical member of the herpesvirus group. The particle consists of a centrally placed capsid exhibiting cubic symmetry, surrounded by an outer envelope which is partially cell derived. In diagnostic electron microscopy it is only necessary to find the internal symmetrical component (capsid), as seen in (b) and (c). The particle shown here is herpes simplex virus, but, morphologically, it could equally well be varicella or herpes zoster. $\times 300,000$. (b) A naked herpes capsid from a case of herpes simplex encephalitis. This micrograph was obtained by simply mixing homogenized brain tissue with a negative stain (phosphotungstic acid) and examining the specimen in the electron microscope. $\times 300,000$. (c) Another herpes-type capsid from a skin vesicle of a patient with herpes zoster and an accompanying zoster encephalitis. $\times 300,000$.
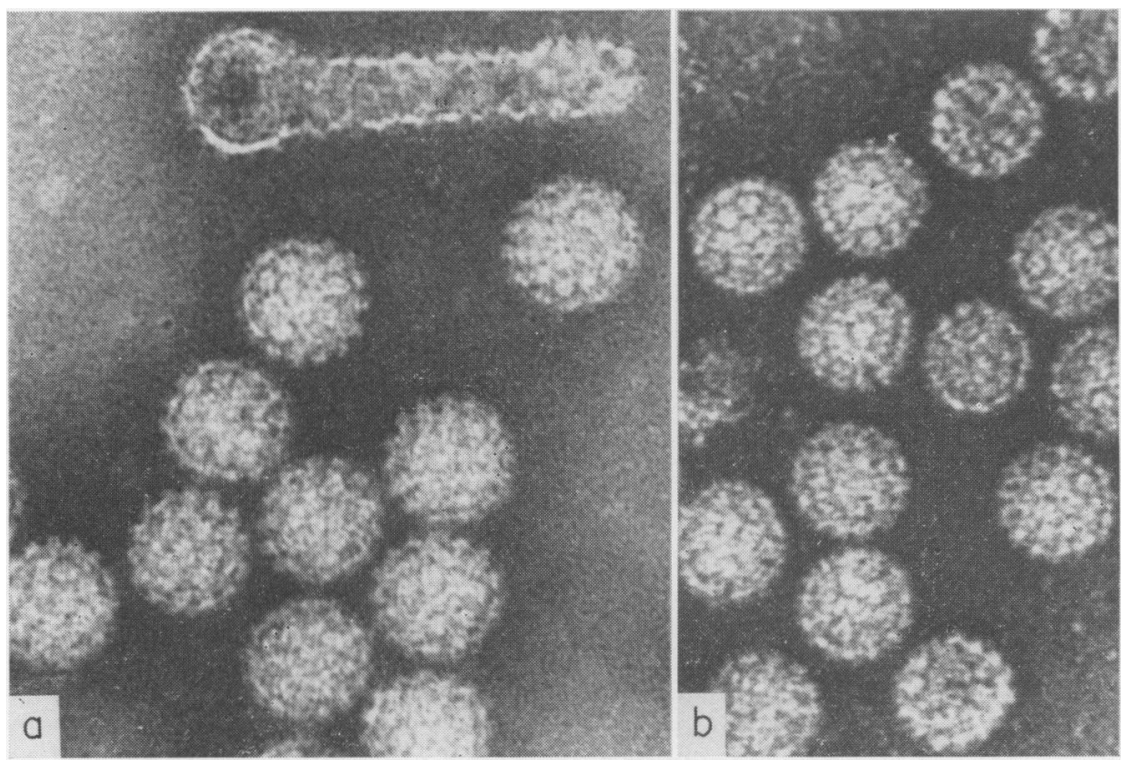

Fig. 4. (a) The lower part of this micrograph illustrates the typical appearance of the human common wart virus. The particles have cubic symmetry and are approximately $550 \AA(55 \mathrm{m \mu})$ in diameter. At the top of the micrograph there is an aberrant tubular form of the virus. This type of structure is of interest as the particles associated with progressive multifocal leuco-encephalopathy (PML) frequently show similar aberrant forms. $\times 300,000$. (b) $\AA$ group of particles of polyoma virus, which has a morphology very similar to the wart virus, but a smaller diameter, approximately $450 \AA(45 \mathrm{m \mu})$. The virus found in the human condition of progressive multifocal leuco-encephalopathy is identical to this, and hence the virus becomes very suspect of oncogenic potential in view of the known ability of several members of this morphological group to cause tumours. $\times 300,000$. 


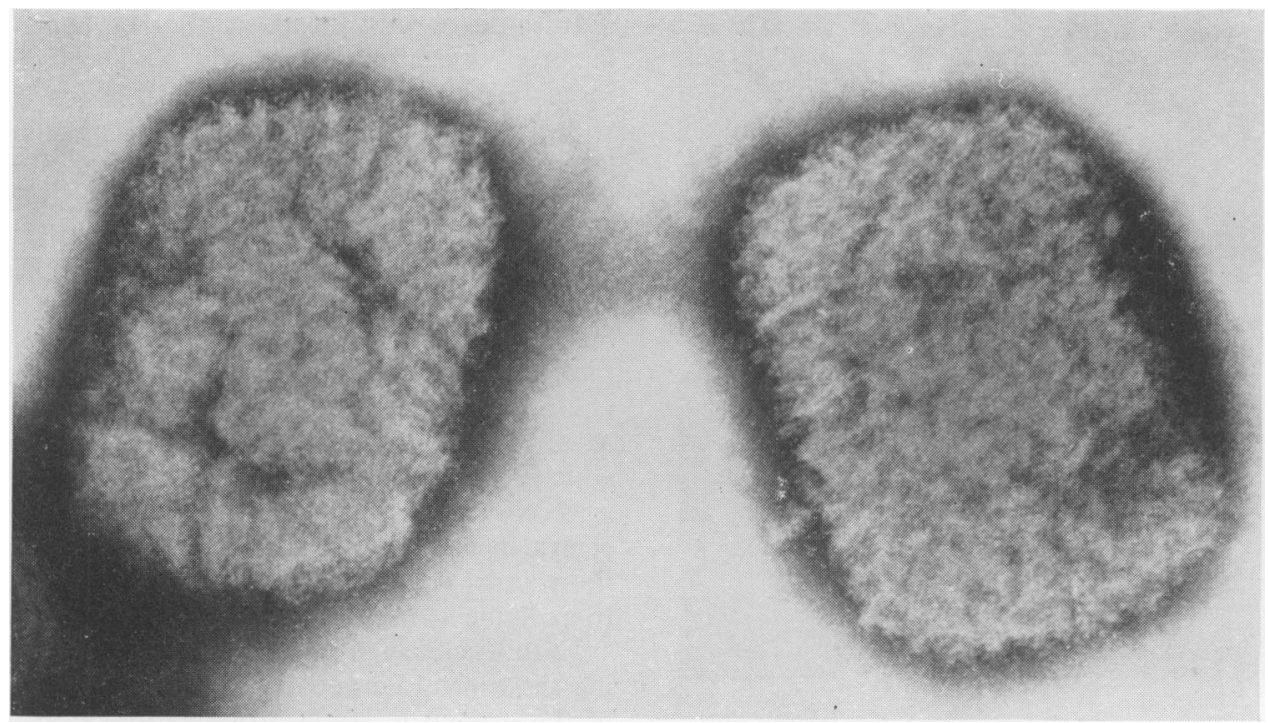

FIG. 5. Two typical negatively stained particles of vaccinia virus. The appearance is characteristic of poxviruses in general and, although the particles are'distinctive, there is no visible symmetry. This in turn means that the poxvirus group is unique in not fitting into one of the physico-chemical groups. $\times 200,000$.

TABLE 1. Physico-chemical grouping of viruses

\begin{tabular}{lll}
\hline Symmetry & \multicolumn{1}{c}{ RNA } & Nucleic acid \\
\cline { 2 - 3 } Helical & $\begin{array}{l}\text { Myxoviruses (e.g. influenza, parainfluenzas, } \\
\text { mumps) } \\
\text { Measles, rinderpest, distemper } \\
\text { Respiratory syncytial virus } \\
\text { Rabies } \\
\text { Enteroviruses (polioviruses, ECHO viruses and } \\
\text { Coxsackie viruses) } \\
\text { Reoviruses }\end{array}$ & $\begin{array}{l}\text { Papilloma viruses (human wart, Shope rabbit } \\
\text { papilloma) } \\
\text { Cubic }\end{array}$ \\
$\begin{array}{ll}\text { Polyoma group (polyoma, SV40, virus of } \\
\text { PML*) }\end{array}$ \\
Hncertain & $\begin{array}{l}\text { Herpesviruses (herpes simplex, herpes zoster, } \\
\text { varicella) } \\
\text { Cytomegaloviruses } \\
\text { Adenoviruses } \\
\text { Poxviruses }\end{array}$ \\
\hline
\end{tabular}

* Progressive multifocal leuco-encephalopathy.

the relative ease with which the cellular changes can be observed by the light microscope, or even by the naked eye, and it has made possible the titration of infectivity by the counting of plaques of destroyed cells in cell sheets.

The second type of response is the oncogenic one, i.e. the transformation of the infected cell to malignancy. Here the cell must not be killed by the action of the virus, but subtly altered so that the normal control mechanisms by which cells are governed in a multicellular organism are lost and the altered cells grow in an uncontrolled manner to form a tumour or give rise to leukaemia. An oncogenic response can be produced by both RNA and DNA viruses, although the mechanism of malignant transformation differs in the two instances. In the case of tumour viruses with RNA, the virus persists in the transformed cells and, with certain reservations, can always be recovered from them. DNA tumour viruses, on the other hand, do not persist in the transformed cells as such, although there is evidence that at least some of their genetic material is incorporated into the genome of the cells.

Thirdly, we come to a kind of virus-host cell interaction which is understood even less well than these last two categories, a situation which we 


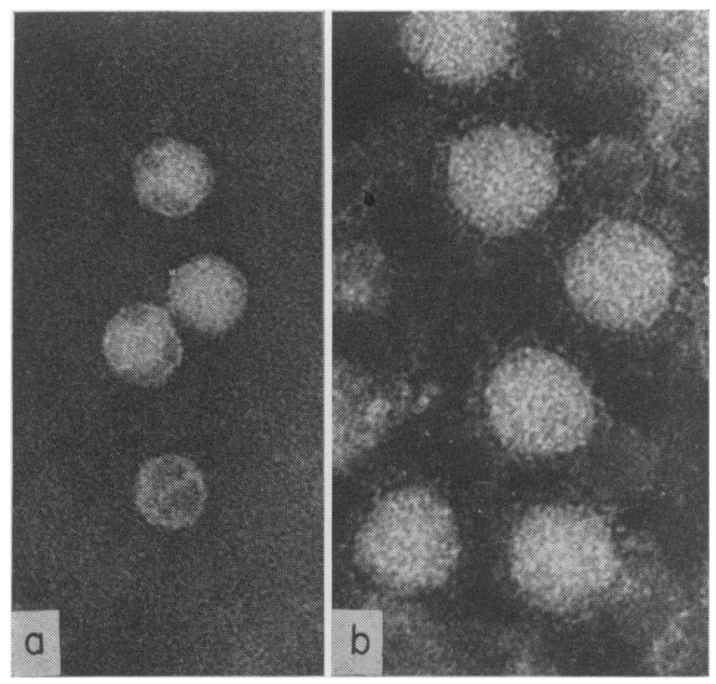

Fig. 6. (a) Four negatively stained particles of ECHO virus 11. Poliovirus is identical in appearance. Although revealing little fine structure in the electron microscope these small RNA viruses are known from X-ray diffraction studies to have cubic symmetry. $\times 300,000$. (b) Six particles of Semliki Forest virus, a morphological representative of the arbovirus group. These viruses are known to be RNA viruses, and, although their symmetry is not yet determined with certainty, it seems likely that they will belong to the RNA-cubic category. $\times 300,000$.

observe even more 'as in a glass, darkly'. In this group the virus can be considered as having entered into a symbiotic relationship with the infected cell, and hence, indirectly, into symbiosis with the organism of which the cell is a part. It appears that this type of relationship can exist not only for years but even for decades, and it is possible that there are more symbiotic relationships in the human body than we at present realize (Johnson, 1967). Eventually, however, some circumstance upsets the delicate balance between virus and cell and the freshly activated virus makes its presence felt by producing one of the two other cell-responses already described.

The ability to produce one, or a combination, of these responses is not resident in any particular class of the physico-chemical groups of viruses. Moreover, one particular virus can, by variation in circumstance or host, elicit different responses. For example, the DNA-cubic group contain the adenoviruses, which in man have been shown to exert only a lytic effect, but which in hamsters produce tumours. Polyoma, a DNA-cubic virus, can be either a lytic or an oncogenic virus, while measles, an RNAhelical virus, can behave either as a simple lytic virus or, in circumstances of some interest to neurologists, enter into a symbiotic relationship with cells of the central nervous system.
In spite of this the possibility of being able to arrange viruses in groups that will not change as more information becomes available (as happened with the earlier concept of 'tropisms') must inevitably lead to an improved understanding of the mechanisms involved in virally induced disease. One of the most important pieces of information that can be obtained about a new virus is its morphology, because when this is known it is possible to look for relationships with known viruses in a much more meaningful way than has previously been possible.

Up to this point we have been looking on viruses as abstract entities and considering the means by which they can be viewed and classified. We shall now consider specifically those which infect the central nervous system, and whether viruses within the central nervous system behave differently from those same viruses elsewhere.

From the viewpoint of a physico-chemical grouping the central nervous system behaves like the rest of the organism, being prone to infection by all of them. Every one of the viral morphologies illustrated in this article could have been obtained from a neurological specimen, and two of them actually were (Figs. $2 b$ and $3 b$ ). It is with regard to the cell response that the central nervous system seems to differ in some respects from the rest of the organism, and so viral infections of the central nervous system will be dealt with under the headings of lytic, oncogenic and symbiotic.

\section{Lytic viruses}

By far the greatest number of viruses implicated in neurological disease fall into this category, and Table 2 gives a list of the viruses that at one time or another have been implicated in acute viral infections of the meninges, brain and spinal cord (McLean, 1967). All of the major groups are represented and the effect in each case is cell infection followed by cell death.

TABLE 2. Some viruses which cause acute infections of the human central nervous system

Polioviruses
ECHO viruses
Coxsackie viruses
Herpes simplex
Herpes zoster (varicella)
Measles
Mumps
Rabies
Lymphocytic choriomeningitis
Arboviruses
Influenza

Acute viral infection of the meninges is accompanied by acute inflammation, and several different viruses can be the cause of a fairly uniform clinical picture, characterized by fever, malaise, headache 
and meningism, and a relatively low count of mononuclear cells in the cerebrospinal fluid, the clinical syndrome being known as aseptic meningitis. These infections, primarily of the meninges, do not usually involve the substance of the brain and cord to any appreciable extent and the outcome is generally benign. However, viral infection of the brain or cord itself, i.e. of the neurones or glial cells, is generally a more serious condition. The destruction of neurones by cytolytic viruses is seen most typically in the anterior horn cells of the spinal cord in poliomyelitis. The neuronal destruction is accompanied by a localized acute inflammation; the damaged neurone is surrounded, and its remains removed, by neuroglial cells.

Acute viral encephalitides can be caused by arboviruses (Fig. 6a), poliomyelitis (Fig. 6b), measles (Fig. 2a), mumps and herpesviruses of various types (Fig. 3a, b and c). The encephalomyelitis seen occasionally after smallpox vaccination probably falls within this category. The reaction in this group of virus-cell interactions is simple and uncomplicated, and similar to infections elsewhere in the body. Cells are infected and die. The disease syndrome results from their loss, from the accompanying vascular disturbance (inflammation, oedema, etc.) and is either self-limiting or leads to the death of the host.

\section{Oncogenic viruses}

If one is dealing solely with man then this category is of necessity restricted as there is no undisputed example in man of a virus giving rise to malignant transformation (Gross, 1961). At present, the nearest to an oncogenic virus in man is the causative agent of the human common wart (Fig. 4a), a condition which has been reported to show malignant change, although very rarely. Whether or not such malignant transformation does take place, the human wart virus is of considerable interest because it bears a close physico-chemical resemblance to the Shope papilloma virus of rabbits; this virus produces non-malignant papillomata in its natural host the cottontail rabbit, and these sometimes proceed to malignancy; in the domestic rabbit these virus-produced papillomata progress much more frequently to malignancy (Syverton, 1952). Again, within this same morphological group, and only slightly smaller than the papilloma viruses, there exists an animal virus that is probably the most powerful oncogenic agent known. This is polyoma virus (Fig. 4) which can kill a hamster with diffuse sarcomata of the kidneys in only 10 days. It is, therefore, of the greatest interest that in a disease of the central nervous system in man frequently associated with cancer (progressive multifocal leuco-encephalopathy, PML.) electron microscopy has recently revealed in oligodendrocytes a virus morphologically identical with polyoma (Howatson, Nagai \& Zu Rhein, 1965; Zu Rhein, 1967). As well as polyoma, this same morphological group contains SV40, a virus which seems not to produce any effect in its natural host, the monkey, but which produces tumours in hamsters on subcutaneous inoculation. This makes the virus found in the brains of cases of PML very suspect indeed, and probably the best candidate at present for a human cancer virus, although a word of caution should be added that this morphological group also contains Kilham's mouse pneumonitis virus, which, in spite of considerable efforts on the part of oncogenic virologists, has never been shown to have any tumour-producing ability whatsoever.

\section{The symbiotic virus-cell relationship}

We have now considered the lytic relationship, which involves cell-destruction with the production of progeny virus and also the oncogenic relationship, which involves malignant transformation of the cell and may or may not involve production of virus. The third type of virus-cell relationship, which may be termed the symbiotic one, is probably the one type of the three which has the most significance for the central nervous system, as there is a mounting list of conditions which seem to be explicable only on the basis of virus remaining dormant within cells of the central nervous system for very long periods of time. These are often the same viruses that almost always behave within the central nervous system in precisely the same manner as they, or their counterparts, do elsewhere in the body, producing a lytic effect, with cell death and accompanying acute inflammation, which is the pathological basis of the encephalitides and meningitides detailed above. Occasionally, however, it would seem that a virus which is usually lytic enters into a different type of relationship with cells of the central nervous system, so that it becomes latent and remains for long periods of time unexpressed either in terms of viral multiplication or cell destruction. Of course, in the present state of our knowledge, it is impossible to say how often this happens, or in what percentage of cases the relationship leads eventually to overt disease, disease occurring when for one of several reasons the balance between the virus and the cell is destroyed, the virus returning to its usual lytic form.

A well-known example of this kind of relationship is the syndrome of herpes zoster (Hope Simpson, 1954). A pre-requisite for an attack of shingles (zoster) is that the patient has had a previous infection with chickenpox (varicella) virus, although the interval between the two events may vary from a few months to as long as 40 years or more. There is now evidence that the virus of varicella and the virus of 
zoster are identical (Fig. 3) and there is increasing evidence that at the time of the attack of chickenpox the virus becomes latent in the cells of the dorsal root ganglion, to be reactivated later by such triggering events as trauma, stress, or general lowering of the effectiveness of the immune mechanisms of the body, or even by further exposure to varicella-zoster virus. This last possibility leads to the speculation that the virus may remain in the central nervous system in some form which renders it incapable of expressing itself and there is a requirement for a fresh infecion with complete virus to reactivate it. It is also of interest that about a third of the patients who develop zoster have a subsequent attack, suggesting that even after activation and expression of the virus some remains once again in the latent form. The phenomenon of zoster is quoted as perhaps the best understood example of this kind of virus-cell relationship in the human central nervous system, and the fact that so much remains to be understood about this syndrome emphasizes our lack of knowledge about the remainder of these conditions.

Before considering individually these conditions of the central nervous system with prolonged latency, it should be remarked that rabies occupies an interesting intermediate position. This disease has the unique feature that the time of infection by a dogbite is usually known accurately, and, while the disease may appear within weeks, it also may not supervene until as long as 2 years have passed. During this time the virus is supposed to progress slowly within the nervous system, so that rabies provides a link between the frankly lytic and the symbiotic types of virus-cell and virus-host reactions that we are discussing here.

The diseases which can be considered as showing evidence of viral symbiosis in their aetiology include two human conditions, progressive multifocal leucoencephalopathy (Richardson, 1961) and subacute sclerosing panencephalitis (SSPE) (Sever \& Zeman, 1968; Dayan, 1969), which are certainly virally caused. Also visna, a demyelinating disease of sheep (Stamp, 1967), and kuru in man (Gajdusek, 1963; Beck et al., 1966; Beck \& Daniel, 1969), can both be transmitted by cell-free filtrates, although so far it has not been possible in either of these two conditions to isolate and characterize a virus.

Visna, a disease of sheep (Thormar, 1967), has been reproduced experimentally by a well characterized virus of the compound RNA type which, at least externally, is similar to influenza. The disease consists of a sub-ependymal proliferation of cells followed by widespread demyelination, the clinical picture being preceded by changes in the cell content of the cerebrospinal fluid. The latent period between inoculation and symptoms may be as long as 2 years.
Subacute sclerosing panencephalitis (SSPE)

This is a disease of children and young adults, typified pathologically by eosinophilic inclusions in neurones, and by astrocytosis. Just as herpes zoster requires previous infection by the same virus as varicella, it appears that an earlier attack of measles of the ordinary lytic type is a pre-requisite for SSPE. Electron microscopy of the brain of cases has revealed structures identical with measles ribonucleoprotein (Tellez-Nagel \& Harter, 1966) (Fig. $2 a$ and $b$ ) in the nuclei of glial cells. This is accompanied by a very high titre of circulating antibody to measles in the serum (Legg, 1967) and a relatively higher level in the cerebrospinal fluid (Connolly et al., 1967). Measles is further implicated in this disease by the fact that fluorescein-conjugated antiserum demonstrates measles-virus antigen in the central nervous system. However, although several attempts have been made to recover measles virus from SSPE brain, this has hitherto not proved possible, so that although there is strong circumstantial evidence that this is an abnormal expression of a normally lytic virus, measles, some reservation must be maintained, as Koch's postulates have not yet been fulfilled.

\section{Progressive multifocal leuco-encephalopathy (PML)}

This condition has already been mentioned. It is arare disease, occurring usually in conjunction with reticuloses. The essential pathology is multifocal demyelination with conspicuous nuclear changes in the oligodendrocytes. These abnormal nuclei contain virus morphologically resembling polyoma and SV40. This virus is almost certainly responsible for the destructive effect on the neuroglia.

\section{Kuru and scrapie}

Kuru (Gajdusek, 1963), a disease found in a localized group of New Guinea natives, and scrapie (Stamp, 1967) a disease primarily of sheep, are characterized by degeneration of neurones in the cerebellum, and to a lesser extent, the cerebrum. They are transmissible to experimental animals by filtered material of a size smaller than $45 \mathrm{~m} \mu$ which may, in the conventional sense, be viral. They both have a long latent period, during which the agent must be residing, in some form, in the central nervous system.

The two viruses at present most implicated in the latent-symbiotic interaction, namely herpes zoster and measles, normally behave as lytic viruses. In addition, herpes simplex encephalitis has been known to be initiated by trauma (Marshall, 1967), which would scarcely be expected to give rise to infection, but may well light up a latent virus. It seems likely, therefore, that it is some peculiarity of the milieu provided by the central nervous system 
which favours the different behaviour in it of the viruses, particularly as measles and the herpes group are, virologically, poles apart, being RNA-helical and DNA-cubic respectively, and showing as a common feature only the fact of compound morphology (i.e. the possession of an envelope).

In what way then, does the environment in cells of the central nervous system differ from that in cells elsewhere in the body? Or perhaps the correct way to word this question would be-which of the ways in which the central nervous system does differ from the rest of the organism are important in the present context? Probably of greatest interest is the fact that the central nervous system would seem to have different immunological status from most of the rest of the body. Immune globulins are only about a tenth as plentiful in the cerebrospinal fluid as they are in the body fluids in general (Clarke, Dane \& Dick, 1965). Also in this context it is interesting that the skin, like the central nervous system, is ectodermal in origin, and both of them are popular hiding places for viruses in search of sanctuary. Perhaps of equal importance is the consideration that neurones belong to a small group of cell-types that are almost completely non-dividing. This could mean that a virus within a neurone would have no pressure exerted on it to maintain itself through the changes and chances of frequent cycles of cell division.

The nature of the relationship between virus and cell during the period when there are no overt symptoms or signs of disease is very little understood. The virus may be present within the cell as mature and intact particles and simply fail to multiply until some external event precipitates this. This is comprehensible in a non-dividing cell such as a neurone. On the other hand, it may be in the cell in a form which contains the complete nucleic acid (or genome) of the virus, but which is nevertheless physically incomplete, e.g. lacking the outer coat in the case of measles or zoster viruses. It may be in a cell in a form which is not only morphologically but also genetically incomplete, lacking perhaps the genetic information for making some essential protein of the virus particle. There is also the possibility that the virus is multiplying very slowly and that eventually the cumulative effect of its multiplication begins to cause symptoms and signs of the disease The last hypothesis could explain not only very long periods without symptoms followed by a relatively sudden onset of disease, but also slowly progressive disorders such as visna.

This last section, although speculative, has for a foundation a basis of experimental and observational facts, e.g. the occurrence of an acute episode during which the viruses concerned could originally have gained entry, followed, perhaps after many years, by a recrudescence of activity of the same virus.

What follows is speculation based on speculation and, therefore, not to be taken too seriously. It does, however, put forward an idea suggesting that the viral population of the central nervous system may be of importance not only to this system itself, but also as a means of obtaining information on the virological history of the organism as a whole. In this connection the virus of PML requires special mention. Oncogenic DNA viruses, as has been stated, do not persist in the tumours they induce and, except for deliberate laboratory experiments when the causative agent is known, it is impossible to say whether or not an existing neoplasm was virally induced. If, however, some oncogenic agent introduced at an early age should be preserved in an immunologically safe place then it might be capable of survival in a more or less inert form for even the whole life span of the host. We know that this happens with the lytic type of virus in the varicellazoster and SSPE situations. We would like to put forward the hypothesis that the virus particles found in the central nervous system in progressive multifocal leuco-encephalopathy are the descendants of an agent which has given rise to a neoplastic condition in the same host, but from which condition it can no longer be recovered.

To sum up, it appears that the nervous system, generally speaking, can be infected by the same viruses which affect the rest of the body. However, some viruses, i.e. rabies, poliovirus and many of the arboviruses, do display true neurotropism, as they exert their most serious and characteristic effect on the nervous system. Apart from these, it appears that the effect of a virus on the central nervous system depends not so much on the agent itself as on the virus-cell interaction which it elicits.

\section{Acknowledgments}

One of us (J.D.A.) is supported by a grant from the Medical Research Council.

We are indebted to Dr Anthony Dayan for material from patients with subacute sclerosing panencephalitis and to Dr J. E. Banatvala for the photographs of the cell cultures illustrated in Fig. 1.

\section{References}

Almeida, J.D. (1963) A classification of virus particles based on morphology. Can. med. Ass. J. 89, 787.

Beck, E. \& Daniel, P.M. (1969) Degenerative diseases of the central nervous system transmissible to experimental animals. Postgrad. med. J. 45, 361.

Beck, E., Daniel, P.M., Alpers, M., Gajdusek, D.C. \& GibBS, C.J. (1966) Experimental 'kuru' in chimpanzees. Lancet, ii, 1056.

Clarke, J.K., Dane, D.S. \& Dick, G.W.A (1965) Viral antibody in the cerebrospinal fluid and serum of multiple sclerosis patients. Brain, 88, 953. 
Connolly, J.H., Allen, I.V., Hurwitz, L.J. \& Millar, J.H.D. (1967) Measles-virus antibody and antigen in subacute sclerosing panencephalitis. Lancet, i, 542.

DAYAN, A.D. (1969) Subacute sclerosing panencephalitis: measles encephalitis of temperate evolution? Postgrad. med. J. 45, 401.

Gajdusek, D.C. (1963) Kuru. Trans. Roy. Soc. trop. Med. Hyg. 57, 151.

Gross, L. (1961) Oncogenic Viruses. Pergamon Press, Oxford.

Hope Simpson, R.E. (1954) Studies on shingles. Is the virus ordinary chickenpox virus? Lancet, ii, 1299.

HORNE, R.W. \& WILDY, P. (1961) Symmetry in virus architecture. Virology, 15, 348.

Howatson, A.F., Nagai, M. \& Zu Rhein, G.M. (1965) Polyoma-like virions in human demyelinating brain disease. Can. med. Ass. J. 93, 379.

JoHNSON, R.T. (1967) Chronic infectious neuropathic agents: possible mechanisms of pathogenesis. Current Topics Microb. Immunol. 40, 3.

LEGG, N.J. (1967) Virus antibodies in subacute sclerosing panencephalitis: a study of 22 patients. Brit. med. J. 3, 350.

LWOFF, A., Horne, R. \& Tournier, P. (1962) A system of viruses. Cold Spr. Harb. Symp. quant. Biol. 27, 51.

MarShall, W.J.S. (1967) Herpes simplex encephalitis treated with idoxuridine and decompression. Lancet, ii, 579.
Mclean, D.M. (1967) Aseptic meningitis. Recent Advances in Medical Microbiology (Ed. by A.P. Waterson), p. 54. Churchill, London.

RichARDSON, E.P. (1961) Progressive multifocal leukoencephalopathy. New Engl. J. Med. 265, 815.

RIVERS, T.M. (Ed.) (1952) Viral and Rickettsial Infections of Man, 2nd edn. Lippincott, Philadelphia.

Sever, J.L. \& Zeman, W. (Ed.) (1968) Measles virus and subacute sclerosing panencephalitis. Neurology, 18, 1.

Stamp, J.T. (1967) Scrapie and its wider implications. Brit. med. Bull. 23, 133.

SwaIn, R.H.A. \& Dodds, T.C. (1967) Clinical Virology. Livingstone, Edinburgh and London.

SYVERTON, J.T. (1952) The pathogenesis of the rabbit papilloma-to-carcinoma sequence. Ann. N.Y. Acad. Sci. $54,1126$.

Tellez-NAGel, I. \& HaRTer, D.H. (1966) Subacute sclerosing leukoencephalitis: ultrastructure of intranuclear and intracytoplasmic inclusions. Science, 154, 899.

THORMAR, H. (1967) Cell-virus interactions in tissue cultures infected with visna and maedi viruses. Current Topics Microb. Immunol. 40, 22.

WATERSON, A.P. (1968) Introduction to Animal Virology, 2nd edn, p. 12. Cambridge University Press, Cambridge.

Zu Rhein, G.M. (1967) Polyoma-like virions in a human demyelinating disease. Acta Neuropathologica, 8, 57. 